\title{
Manuel González Prada: el ritmo de las palabras y el ritmo de las ideas
}

\section{Manuel González Prada: the rhythm of words and the rhythm of ideas}

\author{
Alex Morillo Sotomayor ${ }^{1}$ \\ Universidad Nacional Mayor de San Marcos y Universidad Científica del Sur, Lima, Perú \\ amorillo@cientifica.edu.pe
}

\section{RESUMEN}

Este artículo estudia las correspondencias entre la producción poética y la producción ensayística de Manuel González Prada, considerado uno de los escritores más influyentes en el proceso de modernización de la literatura peruana, a inicios del siglo XX. En un primer momento, se analizan algunas ideas fundamentales del autor en torno a la experiencia poética y el lugar que debe ocupar en el escenario moderno. $Y$ en un segundo momento, se exploran las formas de incursión de tales reflexiones en las estrategias de significación que proponen algunos de sus poemas.

\section{PALABRAS CLAVE}

Manuel González Prada, escritura poética, escritura ensayística, modernidad literaria

\section{ABSTRACT}

This article studies the correspondences between the poetic production and the essayistic production of Manuel González Prada, considered one of the most influential writers in the process of modernization of Peruvian literature, at the beginning of the 20th century. At first, it analyzes some fundamental ideas of the author around the poetic experience and the place that must occupy in the modern

1 Licenciado en Literatura por la Universidad Nacional Mayor de San Marcos. Se desempeña como docente en el Departamento de Literatura de la Universidad Nacional Mayor de San Marcos y en la Escuela de Artes Escénicas de la Universidad Científica del Sur. Su campo de investigación es la poesía peruana. Ha publicado el libro La poética nodal. El nudo y su fundamentación estética en la poesía escrita de Jorge Eduardo Eielson (2014) y el poemario Fragilidad de lo visible (2008). 
stage. And in a second moment, it explores the forms of incursion of such reflections in the strategies of signification that propose some of its poems.

\section{KEYWORDS}

Manuel González Prada, Poetic writing, essayistic production, Literary modernity

Manuel González Prada (Lima, 1844-1918) es recordado por el perfeccionamiento formal con el que ponía a prueba su producción poética. Son conocidas las reformulaciones estróficas que emprendió a partir de la adaptación de modalidades foráneas, como la francesa «rondel», la inglesa «espenserina» y la italiana «rispetto», por ejemplo. Esto lo llevó a ser considerado como uno de los motivadores fundacionales de estas modalidades en la tradición poética hispanoamericana y a ubicarlo como uno de los renovadores de la lírica peruana. Su poesía es asumida también como el punto de encuentro entre diversas estéticas en constante tensión, como la conceptista, la simbolista y la parnasiana (Lino, 2013, p. 70). En lugar de discutir el grado de innovación que trajeron consigo tales reformulaciones, hasta dilucidar si representan una expresión precursora o epigonal de cara al Modernisno y al vislumbramiento de la Vanguardia$^{2}$, lo que busca esta investigación es subrayar que la modernización del quehacer poético peruano en manos de este autor no solo consistió en proponer un laboratorio verbal donde la apertura hacia las influencias estéticas foráneas fue un gesto imprescindible de dinamización cultural ${ }^{3}$.

2 González Prada es un precursor de la poesía posmodernista, sostiene Américo Ferrari, pues su escritura presenta una serie de rasgos originales que dieron forma a la poesía nueva que se abría paso en los primeros años del siglo XX. Está la versión poética gonzalezpradiana de las innovaciones formales y del cultivo de una retórica filosófico-liberal-racionalista en la que «todo parece demasiado nítido y perentorio, rígidamente recortado en conceptos»; pero también está la versión deudora de la tradición hispánica, debido al tratamiento de temas «elevados» y convencionales de lo poético, como la naturaleza, la amada, la felicidad, la humanidad, la belleza, el tiempo, la muerte, el porvenir; para enriquecer el entramado aparece la versión de una «faz oscura» en la que priman los sentimientos de turbación, de congoja y de desamparo, donde justamente se deja de lado el mensaje programático y la exposición de la razón como una facultad plena y absoluta, acercándola a una clave impresionista y sugerente; y a todo esto hay que sumar la progresiva depuración del lenguaje y la economía de recursos - como ocurre en Baladas peruanas y Trozos de vida - hasta llegar a composiciones breves y apretadas que guardan ciertas semejanzas con el haiku (2003, pp. 310-325).

3 En José Carlos Mariátegui encontramos al menos tres argumentos a favor de la modernización de la literatura y de la cultura peruanas desde la producción creativa y crítica de González Prada: en primer lugar, su espíritu cosmopolita, forjado en el centro de la tormenta de un escenario que no tenía cómo arraigar la idea de peruanidad, al demandar una «liberación de la metrópoli» y una oxigenación de la letra nacional a partir de paradigmas culturales occidentales, representó en ese momento una alternativa nueva de la literatura peruana. En segundo lugar, aunque la propuesta gonzalezpradiana no revela un conocimiento profundo sobre la realidad indígena, y por eso mismo no logró convertirse 
Es importante comprender también cómo la escritura poética de González Prada supo transmitir una especie de «intelectualismo sentencioso» (Salazar Bondy, 2014, p. 275).

Esta última atribución es el punto de partida elegido para problematizar una polarización que la crítica especializada ha avalado por mucho tiempo y que tiene que ver con dividir la figura del escritor peruano entre el ideólogo y el creador. Antes que una división, la comprensión que demanda la obra de González Prada es una forjada en la integración de sus distintas formas de escritura desde y sobre la literatura. En tal sentido, el despliegue técnico que reflejan sus versos y la disposición para teorizar sobre el verso castellano - como lo demuestran, por ejemplo, las notas que aparecen en Minúsculas (1901) y Exóticas (1911), y más aún la teorización que emprende en su trabajo titulado Ortometría (1977)—, así como los diversos ensayos que concentraron su atención sobre la poesía, dan como resultado un conjunto de propuestas discursivas que se aprecian a plenitud en su enriquecedora retroalimentación ${ }^{4}$.

Una de las inquietudes más interesantes en el pensamiento gonzalezpradiano tiene que ver con el alcance y las condiciones del ejercicio de la escritura, y sus múltiples modalidades, en la incipiente y convulsionada cultura republicana de nuestro país, a finales del siglo XIX e inicios del siglo XX. En el ensayo titulado «Libertad d'escribir», González Prada denunció abiertamente las restricciones sobre la libertad de expresión, tanto en el ámbito artístico —cuando existían las «comisiones de espectáculos» que censuraban una dramaturgia que se presentaba en el medio local—, como en el campo periodístico — cuando la escritura de un periodista era

en un programa que apuntara a resolver las situaciones conflictivas de dicha realidad, representó «el primer instante lúcido» de la conciencia del Perú, puesto que posee el germen del nuevo espíritu nacional al considerar a la masa indígena el fundamento de lo peruano, descentrando el lugar privilegiado de la clase criolla. Y, por último, denunció al colonialismo, dejando al descubierto el desfase de sus lógicas y mecanismos de cara a una nueva era de las realidades americanas (1980, pp. 254-258).

4 Para Camilo Fernández Cozman, la conciencia crítica del poeta moderno en el proyecto estético-ideológico de González Prada se aprecia en las correspondencias que existen entre la producción teórica sobre el verso, palpable en Ortometría, y su producción poética, específicamente en su primera entrega, Minúsculas, de modo que aquello que plantea en su tratado de métrica lo practica en su escritura poética. El crítico señala también que la poesía de González Prada se acerca más al Parnasianismo que al Simbolismo, por lo que no se desarrolla en ella una estética de la sugerencia ni presupone un lector activo (2005, pp. 15-20). No obstante, lo que hay que preguntarnos en casos como estos es si solo podemos identificar como sugerente un lenguaje caracterizado por el artificio, la abstracción y el efecto impresionista, o si hay otras maneras de pensar la sugerencia. Y, en consecuencia, sí puede ser sugerente el hecho de encontrarnos con un tipo de escritura que en varias ocasiones objetiva la cuestión poética, y con ello la experiencia de conocimiento que trae consigo la poesía, porque traza la imaginen de un lector capaz de reconocer en esa experiencia un rasgo fundamental que lo compromete a repensar su realidad en el lenguaje, convirtiéndolo precisamente en un receptor activo. 
sancionada mediante multas o su autor era condicionado a desembolsar depósitos para ganar un espacio mínimo de divulgación y autonomía-; de modo que la suerte de la producción de un escritor reflejaba muy bien los poderes que regían a la sociedad:

Todos los Gobiernos, al inaugurarse, «ofrecen garantías a la emisión del pensamiento, i se congratulan de ver en la prensa o cuarto poder del Estado un colaborador intelijente para la magna obra de la rejeneración nacional». Otorgan unos pocos meses de respiro i desahogo; pero insensiblemente resbalan por la pendiente del abuso i concluyen por justificar a los anteriores Gobiernos. Entonces regresamos a la vida normal: en nuestro régimen político, la legalidad i la justicia figuran como breves interregnos.

\section{[...]}

Toda prensa con mordaza termina por engolfarse en la pornografía, la lucha individual i el interés casero. El periódico no es ya río que sale de madre para fecundizar el campo, sino mal canalizado albañal que con sus miasmas pestilentes infecta el aire de la ciudad.

[...]

Con la palabra sucede lo mismo que con el agua: estancada, se corrompe; movida i ajitada, conserva su frescura (1985a, pp. 153-154).

La reflexión desarrolla mejor su crítica enérgica cuando emplea el recurso metafórico del agua, el sentido preciso para edificar la siguiente lógica: la palabra, cuando es parte de un ejercicio de lenguaje y de pensamiento problematizador — «agua movida i ajitada»—, es capaz de «regenerar» los tejidos de la sociedad. De esta manera, González Prada apela a una concepción orgánica y vitalista de la escritura para destacarla como una de las vías más «fecundas» de la civilización. En consecuencia, son vitales aquellos oficios escriturales provenientes del campo estético o del periodístico, porque exploran agudamente la razón de ser del individuo en el espacio público, es decir, su lugar y el lugar de los demás en la cultura; por otro lado, son prácticas que sirven de puente entre el ciudadano común y el creador-intelectual, un puente por donde fluyen las ideas de identidad, sociedad, diversidad cultural, entre otras, que el artista dispone como objetos de asedio constante.

Otro aspecto interesante de la visión vitalista y orgánica de González Prada es que se trae abajo la lógica dualista, propia del paradigma cultural clásico, que separa la espiritualidad de la materia o la fuerza psíquica de la fuerza física en el hombre: «Que apliquemos nuestra fuerza a escribir o a sembrar, no quiere decir que la fuerza varíe de origen o de naturaleza 
ni tenga mayor o menor dignidad $\iota^{5}$. Desde esta perspectiva, en prácticas estéticas como la poesía, la energía que da vida a los vuelos interiores y abstractos de la imaginación es tan productiva como la de cualquier otra práctica social, porque restituye el componente ético de la palabra al recolocarla como la puesta en acto de la modernización tanto del agente creador como del agente receptor.

Parte de dicha productividad tiene que ver también con la redefinición del quehacer artístico a partir de otros ejercicios modernos del conocimiento. Por ello, en ensayos medulares como «Notas acerca del idioma», advertimos el esfuerzo de González Prada por buscar nexos entre la ciencia y el arte: plantea, en primer lugar, que la «vulgarización científica» es la mejor alternativa para que las reflexiones elaboradas y profundas de naturaleza científica puedan ser comprendidas por los individuos que encarnan el sentido común de la sociedad. Llama a los gestores de esta expansión del conocimiento «vulgarizadores modernos» y los considera fundamentales para la dinamización de los saberes. En esa misma línea de reflexión, afirma que las obras de arte más excelsas son aquellas que se abren paso hacia una comunidad mayor, rompiendo el hermetismo de los entendidos. En su accesibilidad está su maestría, y los gestores de la misma son los creadores que cultivan un «injenio democrático». La suerte es contraria para las obras que pretenden el reconocimiento desde la inaccesibilidad, porque «disimulan lo vacío del fondo con lo tenebroso de la forma» (1985c, pp. 255-256).

De la visión gonzalezpradiana se desprende, entonces, que el hermetismo, exacerbado hasta las formas más entramadas del lenguaje, y sea cual fuere la disciplina del saber involucrada, termina por desenfocar el deseo del hombre de reinventar los modos de socialización que le permite el bien compartido de la palabra. Por otro lado, al rescatar el potencial comunicativo del arte poético, el autor evita caer en un reduccionismo mimético y más bien reconoce el poder de la sugerencia como la construcción activa a partir de la cual el creador inventa un lugar de intervención inédita sobre el lenguaje y sobre la razón, para el lector: «el buen escritor no dice demasiado ni mui poco i, eliminando lo accesorio i sobrentendido, concede a sus lectores el placer de colaborar con él en la tarea de darse a comprender» (p. 256). Poetizar es, a fin de cuentas, la intervención conjunta sobre aquel recurso que en otras circunstancias de la vida se presenta en realidades expresivas fragmentadas y aparentemente inconexas.

5 En «Escribas y retóricos» (1985b, p. 357). 
La articulación ciencia-arte, en el pensamiento gonzalezpradiano, tiene un tercer punto de apoyo en la lengua. En el ensayo citado se reflexiona sobre la naturaleza, los desafíos y las problemáticas del idioma castellano en la realidad americana, del mismo modo sobre su evolución en España. Se toma en cuenta la evolución del vocabulario gracias al enriquecimiento brindado por las disciplinas científicas, los contactos idiomáticos y las reformulaciones verbales en medio de las diversas actividades cotidianas del hombre. Se da un tiempo, además, para contrastar el destino de los idiomas, y reconoce en el inglés, por ejemplo, su proyección globalizadora al catalogarla de «lengua universal», debido a su despliegue comercial. Cierra este conjunto de ideas destacando de la figura del escritor la capacidad que tiene para estereotipar en sus obras la lengua de sus contemporáneos, sin perder su propio estilo literario. La premisa resultante de la articulación descrita es que la escritura poética se suma a un ciclo de renovaciones de expresiones y formas de pensamientos, en un contexto moderno de revoluciones comunicativas y tecnológicas: «Aquí, en América i en nuestro siglo, necesitamos una lengua [...] donde se perciba el golpe del martillo en el yunque, el estridor de la locomotora en el riel, la fulguración de la luz en el foco eléctrico i hasta el olor del ácido fénico, el humo de la chimenea o el chirrido de la polea en el eje» (p. 268). De apuntes como estos, parece desprenderse la idea de que la poetización de la lengua no solo pasa por retener las materializaciones de la modernidad como un contenido, sino también por configurar una nueva realidad de lenguaje cuyo registro multisígnico sea capaz de conectar con la expectativa sensorial de un lector que, por así decirlo, está aprendiendo a leer poesía modernamente. El lenguaje poético sería, entonces, una manifestación en la que germina una sensibilidad revolucionaria no porque se oponga a la ciencia o a la lengua natural, sino más bien porque las asimila creativamente desde un registro revitalizador y democratizador, con el fin de dinamizar la idea de lenguaje en los ciudadanos.

En el ensayo «La poesía», González Prada refuerza la idea de que el ejercicio poético debe renovar sus fundamentos en los conocimientos que representan el escenario moderno del hombre. Demanda de los versos un espíritu científico y didáctico que logre transmitir, mediante la imagen y el ritmo, las conquistas cognitivas que están inaugurando el siglo XX. El saber forjado por el artista, junto a las otras aventuras humanas como la filosofía, la historia y los diversos razonamientos científicos, fluyen en «líneas paralelas»; pero la evolución de estas líneas desencadena, a fin de cuentas, un entrecruzamiento enriquecedor, y todo lo que surja de allí se vuelve insumo retórico para el quehacer poético: «Al descubrirse las relaciones íntimas de las cosas, brotan las figuras retóricas y, por consiguiente, 
se ensancha el horizonte poético» (1985d, p. 343). El paralelismo, la evolución continua y el eminente entrecruzamiento son fenómenos rítmicos, y precisamente la convicción gonzalezpradiana de una nueva poesía pasa por un fundamento rítmico, al plantear que el verso debe armonizar el ritmo de la palabra y el «ritmo silencioso» de la idea.

Sin embargo, la convicción no coincide con la realidad, pues el diagnóstico del autor sobre aquel momento fue que la poesía no sintonizaba con los nuevos aires de la modernización, y en consecuencia no se libraba de la imaginería decimonónica que tuvo en la religiosidad y en el patriotismo dos motivaciones claves. Sus cultores aún vivían encapsulados en paradigmas desfasados y cultivaban un «espíritu regional y estrecho». No se abrían conscientemente hacia una nueva sensibilidad que conjugara el trabajo con el lenguaje y el gesto de actualizar su rol de mediadores culturales desde una visión cosmopolita. Antes que poetas sintonizados con el mundo eran «versificadores» que habían caído en el ejercicio mecánico de la técnica. Se dedican a hacer versos pero «no piensan en verso». Pese a ello, González Prada alimenta la expectativa de una poesía moderna a la que le corresponde «el canto de la razón»: el canto que supera los abordajes temáticos tradicionales y las parcelas del pensamiento, y es parte del espiral de saberes y estilos que retratan la aceleración del devenir moderno del hombre.

En estas reflexiones se perciben los derroteros que las vanguardias seguirán en los años posteriores, más aún si la duda y la negación son para el autor los principios del canto moderno de la poesía: «La duda y la incertidumbre desenvuelven a nuestra imaginación un espacio sin límites. Al dudar, afirmamos nuestra personalidad, crecemos, nos sentimos más hombres. La duda patentiza la virilidad del pensamiento». Más adelante precisa: «Los trozos más célebres de las antologías, los versos que más brillan en el tesoro poético de la Humanidad, se hallan impregnados de negación y duda, no de evaporaciones místicas ni delicuescencias dogmáticas» (p. 338). Los principios aludidos, en efecto, dictan las coordenadas del poema que revela su modernidad mediante un lenguaje subversor de los andamiajes simbólicos que tradicionalmente lo legitimaban como una construcción armoniosa, idealizadora y plena. De hecho, son los principios convocados para la exploración de las nuevas estructuras y las nuevas operaciones de la poesía que se asomaban en el horizonte temprano del siglo XX (Friedrich, 1974, pp. 27-31).

Volvamos a la propiedad fundamental del ritmo para comprender el valor de González Prada en el contexto de la modernización de la tradición poética peruana. Para este autor, dicha propiedad supera la condición de efecto tras el tratamiento esmerado del verso y se consolida como el 
recurso desde el cual se piensa y se edifica el quehacer poético. En un ensayo titulado «Víctor Hugo», afirma que una de las virtudes del romántico francés fue lograr la «emancipación del pensamiento» en el arte. Suma a este rasgo el enriquecimiento del lenguaje poético a partir de la inclusión de voces científicas y locuciones populares, así como la renovación del repertorio retórico. Precisa, además, una atribución que bien vale destacar:

Tiene versos lapidarios que encierran síntesis admirables, ideas que parecen presentimientos de leyes científicas o tajos de luz abiertos en lo impenetrable. Hasta cuando el pensamiento se pierde en las abstracciones metafísicas o en las nebulosidades apocalípticas, el verso conserva su inimitable sonoridad, i produce el efecto de música subterránea o recuerda el rítmico galope de un caballo en las tinieblas (1985e, p. 188).

Detrás de todas estas consideraciones existe una conceptualización poética que las entrelaza y que, al mismo tiempo, fundamenta la apuesta estética e intelectual de González Prada: la poesía moviliza el pensamiento, y en consecuencia rompe su mimetismo con el lenguaje, que deja de actuar a su vez como los surcos de la plantilla por los que se vierte una racionalidad automatizada e instrumental. Emancipado el pensamiento, el lenguaje es extralimitado y deconstruido por el quehacer poético hasta conseguir de él la reingeniería verbal que exprese, antes que nada, el sentido de la creación, sin el cual no podríamos seguir construyendo comunicación y conocimiento. Y la emancipación y la reingeniería aludidas no serían posibles sin el factor rítmico que nos ayuda a salir a «galope» de las «tinieblas» del mimetismo. Si para González Prada el ritmo es un fundamento que nos obliga a explorar una idea de poesía desde los mismos dominios del poema, es porque tiene la fuerza suficiente para llevarnos a repensar el lenguaje y su conocimiento solidificado en saberes inconexos e inmediatistas; de modo que dejamos de ser intervenidos por la instrumentalización hegemónica del lenguaje para intervenir al lenguaje desde una conciencia renovada de la expresión y de la sociabilidad.

Y si hablamos del ritmo, cabe recordar la propuesta que encierra el estudio titulado Ortometría. Se trata de una indagación sistemática y rigurosa sobre la naturaleza y la materialización del ritmo desde su componente esencial, el acento. Para el pensamiento gonzalezpradiano, la realización del ritmo es impensable sin la distribución de tiempos que marca el acento sobre las sílabas, las cuales se organizan en «unidades rítmicas» (unidades que reúnen sílabas acentuadas y no acentuadas), y todo ello junto al significado, en lo que constituye un engranaje complejo que da vida a la expresión poética. En suma, el acento es el componente primordial que define la anatomía, la fluidez, las variaciones de intensidad y los 
énfasis semánticos de los versos. La teorización llevada a cabo en Ortometría juega, por lo visto, un rol importante: demanda que reconozcamos en el panorama poético peruano, enmarcado en una modernidad fundacional, un programa orgánico conformado por una serie de propuestas estéticas que, pese a sus diferencias, encuentran en el ritmo el principio edificador ideal para renovar la práctica y la reflexión de lo poético ${ }^{6}$.

Veamos ahora cómo los asuntos estéticos resumidos hasta el momento ocupan un lugar privilegiado en las construcciones ficcionales poéticas del autor. Son provechosos, en ese sentido, algunos textos de Minúsculas, un conjunto de poemas que articula la indagación por los fundamentos esenciales de la condición humana - el porvenir, la muerte, el amor, la felicidad - con una exploración de la naturaleza en cuanto a sus fuerzas, ciclos y múltiples manifestaciones. Entre las diversas modalidades estróficas que evidencian los poemas - y cuyas adaptaciones, respecto a las variaciones métricas y acentuales, son aclaradas en las notas que acompañan al libro - encontramos una espenserina que concentra muy bien la lógica positivista que reviste al trabajo lírico de González Prada:

Después de errar sin brújula ni guía,

Tras años de locuras y demencia,

El pie movemos en segura vía,

Compramos el saber y la prudencia.

Somos un alto luminar de la ciencia,

En medio de la noche tenebrosa;

Mas cuando usar queremos la experiencia,

Es tarde ya: la muerte nos acosa

Nos coge, nos empuja al hondo de la fosa (1988, p. 202).

La fórmula poética que exalta la racionalidad moderna despliega una metaforización doble y complementaria. La primera expresada en códigos

6 Eduardo Lino da cuerpo a ese programa al revelar los vínculos posibles entre González Prada, Valdelomar y Eguren. Sostiene, además, que uno de los objetivos de Ortometría fue sumar argumentos a favor de la autonomía del sistema prosódico español y, por extensión, de su sistema de versificación. Para ello, González Prada se esmeró, por un lado, en clasificar una serie de combinaciones versales de acuerdo con el número de sílabas y la ubicación de los acentos; y por otro, en contrastar los sistemas prosódicos latino y español. Esta estrategia de métrica comparada le permitió exponer dos sistemas de versificación: a) la versificación cuantitativa, considerada en la tradición latina una forma erudita y oficial que se basaba en la distribución del ritmo a partir de las sílabas largas y breves, y b) la versificación acentuativa, identificada con expresiones populares y no oficiales, y que consistía en la particular ubicación del acento léxico como la base de la versificación y de la formación del ritmo. Y en tanto se ponga en perspectiva el cultivo rítmico de la palabra en términos de su despliegue en la oración, son otros los factores influyentes, como la entonación y las pausas. Desde la modalidad acentuativa se erige una concepción estructural y coherente del verso. La emancipación del sistema prosódico español pasa por admitir que la cantidad silábica, aunque es un factor presente en todas las lenguas, no es un criterio determinante en su devenir (2013, pp. 72-90). 
sensoriales: la razón creadora luminiscente en medio de la oscuridad de la ignorancia. Es preferible hablar de luminiscencia para graficar mejor la idea de que el conocimiento moderno es una luz que interviene, transgrede y transforma la tradicionalidad oscura de los conocimientos anteriores, premodernos, prelógicos — los «años de locuras y demencia»—; de modo que el conocimiento moderno se expone en su más deslumbrante fuerza creadora al dialectizar el horizonte cognitivo del hombre. Es interesante cómo ese campo de batalla cognitivo, donde diversas fuerzas intelectuales luchan, es descrito desde un lenguaje también moderno, toda vez que el saber es un bien negociable. El lenguaje comercial empleado cumple con acercarnos a una subjetividad que está a la vanguardia porque lucha intensamente por su sofisticación, por encarnar un estado de reinvención y expansión incesante.

La segunda metaforización se hace presente a partir de un código espacio-temporal: la subjetividad lírica contrapone, en primer lugar, la errancia premoderna con el paso firme, encausado, del devenir cognitivo moderno. Una errancia que se aprecia en una irremediable desaceleración, frente a la marcha vertiginosa del ciclo de las revoluciones teóricas y tecnológicas. Por otro lado, luz y oscuridad simbolizan el destino humano ascendente o descendente, respectivamente, en torno al mito moderno del progreso. El poema se encarga de marcar el ritmo de las ideas sobre este mito, trazando un recorrido desde una primera edad del hombre una ceguera infantil en la que todo es oscuridad - hasta la edad madura de la lucidez y la revelación continua ante la complejidad infinita del mundo. El texto, por lo tanto, interviene creativamente el lenguaje para hacer la historia, pero es una historia que no cae en el simple recuento de los hechos que transforman el destino en cuestión; busca más bien mostrar las tensiones de la condición humana en medio de tales hechos: una humanidad construyéndose, luchando con sus versiones anteriores y tentando nuevas configuraciones. El poema está ahí para decirnos cómo el hombre pone a prueba su expectativa vital a partir de la atmósfera progresista que lo envuelve, y nada menos que repensando el verdadero sentido de la muerte como ese desborde y esa aceleración de un universo tecnológico que él apenas puede nombrar y experimentar.

Cuando el hombre negocia sus experiencias más trascendentes con el desborde y la aceleración, surge la idea de la Belleza como el acontecimiento que lo reposiciona en un plano de conciencia mayor, tal y como se aprecia en una de las balatas del poemario:

De cuantos bienes atesora el mundo, El bien supremo, el de mayor grandeza, Emana de tus formas, oh Belleza. 
¡Poder! ¿Qué vale dominar al hombre?

¡Oro! ¿No mancha corazón y mano?

¡Gloria! ¿Sabemos si es vacío nombre?

¡Nobleza! ¿Torna en águila al gusano?

Todo a mis ojos aparece vano:

Yo solo admiro, oh gran Naturaleza,

El ritmo de las formas —la Belleza (p. 203).

El poema se luce a partir de una operación que subvierte las valoraciones sobre lo que se asume como una posesión progresista. Salta a la vista la dinámica de desmontaje que los signos de puntuación de la segunda estrofa estimulan: las palabras encerradas en las exclamaciones, que dan cuerpo a las ideas abanderadas del progreso, son inmediatamente neutralizadas por las frases que las atraviesan bajo la fuerza de las interrogantes, que dan cabida a la sospecha. La neutralización las vacía del sentido de la productividad y las convierte en los restos verbales que solo pueden signar su propia desnaturalización. El yo lírico aprovecha el vaciamiento y emprende la reingeniería de las cargas significantes, que trabajan ahora para la restitución del sentido de la belleza, una restitución que reconocemos de tres maneras: primero, la duda es la estrategia que pone en escena la subversión de los valores, y por ello se consolida como un ejercicio intensamente creativo, dado que sospechar es renombrar, y renombrar es reposicionar la conciencia del lector, quien parece ser interpelado desde una interrogante mayor: ¿el «bien supremo» de la belleza consiste en desarmar y rearmar las palabras para que podamos movilizarnos críticamente por entre las ideas que sostienen la cultura del progreso? Segundo, la belleza, al ser pluralizada («tus formas») y concebida como una de las mayores aspiraciones del hombre, está convocada desde su organicidad, porque se erige en el fin último de todas las prácticas sociales modernas; de modo que el sentido de productividad que albergaban las palabras pierde consistencia si es que no se inscribe en una expectativa genuina de vitalidad, simbolizada en esa «gran Naturaleza». Y tercero, la estrategia animista, de la que se desprende el diálogo entre la subjetividad lírica y la belleza, revela una visión rítmica del mundo, pues el ritmo aparece como el desencadenante fenoménico de la realidad («el ritmo de las formas») y, a la vez, como la vía de incursión que necesita dicha subjetividad para reingresar sensibilizado a ella.

El ritmo es un insumo retórico clave para la estética gonzalezpradiana, como lo demuestra otro poema del mismo conjunto titulado «Ritmo soñado»: 
Sueño con ritmos domados al yugo

Del rígido acento,

Libres del rudo carcán de la rima.

Ritmos sedosos que efloren la idea,

Cual plumas de un cisne

Rozan el agua tranquila de un lago.

Ritmos que arrullen con fuentes y ríos,

$Y$ en el Sol de apoteosis

Vuelen con alas de nube y alondra.

Ritmos que encierren dulzor de pañales,

Susurro de abejas,

Juego de auroras y nieve de ocasos.

Ritmos que en griego crisol atesoren

Sonrojos de virgen,

Leche de lirios y sangre de rosas.

Ritmos, oh Amada, que envuelvan tu pecho,

Cual lianas tupidas

Cubren de verdes cadenas al árbol (p. 206).

El ritmo alcanza en el poema dos realizaciones fundamentales. Una de naturaleza estructural, y esto se nota en la aplicación regular de varios factores: la organización triádica de los versos; la metrificación uniforme compuesta por endecasílabos en los versos impares y hexasílabos en los versos pares; la distribución acentual con un particular énfasis en las cuartas, sétimas y décimas sílabas, para los versos impares, y en las segundas y sextas sílabas, para los versos pares; del mismo modo la marca textual que inicia cada estrofa, desde la segunda, y que da cuenta de un tejido anafórico a partir de la palabra «ritmos». Entonces, se puede decir que, en términos formales, el texto evidencia una composición moldeada por la performancia rítmica que integra diversos niveles.

Por otro lado, el ritmo alcanza una realización conceptual, específicamente metapoética. Una primera señal de este tipo de realización es la significativa variación respecto al engranaje anafórico en la primera estrofa a partir de la palabra «sueño», pues se erige en la entrada hacia esa subjetividad lírica que opera sobre el lenguaje la proyección del poema futuro. Y en función de dicha futuridad, se contrapone en la primera estrofa el acento - los puntos de apoyo del devenir rítmico- y la métrica - el condicionamiento y ordenamiento cuantitativo-, con la intención de referir el desmontaje productivo de la segunda a favor del primero. Ya 
se había visto antes la importancia del factor acentual en Ortometría, y la misma argumentación se brinda en las notas que acompañan a Exóticas, donde González Prada señala, refiriéndose a la poetización del idioma castellano, que la versificación se funda principalmente en el acento, por lo que la cadencia, antes que la medición, es su estímulo primero: «Hay hermosas composiciones sin rima; pero no cabe imaginar verso castellano sin acentos disciplinados» (p. 349).

Otro aspecto de la conceptualización aludida tiene que ver con la idea del ritmo como una fuerza que orquesta los sentidos. El ritmo concentra y despliega el poder de la sugerencia — representada muy bien por la imagen de las plumas que rozan el agua-, de modo que sin el primero no existe la segunda. La palabra, en consecuencia, en tanto una materialidad depositaria del sentido, no activa por sí sola la significación sugerente. Sin el ritmo desencadenante es solo materialidad o insumo lingüístico que ha desbaratado la configuración ordinaria del lenguaje. El ritmo potencializa dicho desbaratamiento y lo expone como la movilización que desapega el pensamiento del lenguaje, con tal de que se ponga a prueba las reales condiciones de significación de este. De esta manera, la refundación creativa del lenguaje, por parte de la poesía, anuncia que, en realidad, el soporte de «la idea» es el ritmo, y la parte más visible —la punta del iceberg - de dicho soporte es la palabra. La movilización referida, al liberar al lenguaje, nos propone como conocimiento revelador que el ritmo es la propiedad que no solo hace al poema, sino también lo piensa.

Finalmente, las imágenes extraídas del campo semántico de la naturaleza — cuyo tratamiento elevado o solemne inscribe al poema en la estética modernista - y distribuidas a lo largo del texto terminan por reforzar el sustrato rítmico de la sugerencia: arrullos asociados a fuentes y ríos, el vuelo ligero — de nube —, el susurro de abejas, etc. Así, para la subjetividad lírica, la naturaleza y el poema deseado comparten el hecho de que la orquestación de sus elementos se da a través de un dinamismo sutil, incesante y envolvente, como se sugiere muy bien en la última imagen que compara a la amada cautiva con el árbol encadenado por lianas tupidas, para dar a entender al ritmo como un encadenamiento vivificante.

Un ejemplo más de Minúsculas será el pretexto final que utilizaremos para aproximarnos al alcance del factor rítmico en la práctica poética gonzalezpradiana:

¿Son inviolables doncellas los léxicos?

¿Son las palabras sagrados cadáveres,

Momias de reyes, en pétreos sarcófagos?

Son las palabras libélulas vivas: 
Yo las atrapo, si rasan mis sienes;

Yo, palpitantes, las clavo en mis versos.

Vengas de Londres, de Roma o París, Sé bienvenida, oh exótica voz, Si amplio reguero derramas de luz.

¡Guerra al vetusto lenguaje del clásico! ¡Fuera el morboso purismo académico! Libre y osado remonte el espíritu.

Vista ropaje del siglo la idea:

Deje el raído jubón de Cervantes, Rasgue la vieja sotana de Lope.

Tímido esclavo del Verbo ancestral, No ames el águila, el cóndor ni el rock:

Ten de Pegaso un dormido avestruz (p. 211).

La palabra, en tanto una materialidad repensable, se coloca en el centro del ejercicio dialéctico del poema, que en sus dos primeras estrofas plantea dos momentos claramente diferenciados: en el primero, la palabra es tratada como una huella enigmática, la depositaria de una significación que se ha sedimentado con el paso del tiempo. El peso histórico de la racionalidad sobre el lenguaje hace lo suyo y nos recuerda que la palabra es revestida por una espiral interminable de usos y reformulaciones, recontextualizaciones y decontextualizaciones; en suma, capas y capas de sentido. En estos primeros versos, la palabra es una corporalidad que en el tránsito de su desmaterialización — «cadáveres», «momias»- y revela sus conexiones más profundas con la cultura. La sacralidad y el poder que envuelven a estos restos corporales yace, precisamente, en la posibilidad de contener y revelar una totalidad — una visión de mundo- a pesar de su fragmentada y vulnerable consistencia.

La exposición a la luz de esos vestigios necesita, precisamente, de un agente como el poeta que se anime a atravesar las capas profundas y compactas del lenguaje: una sensibilidad que sea capaz de remover dichas capas para traerse abajo el mito falso de que las palabras ya se colmaron de cultura y, por ello, ya no admiten más reinvenciones. La simbolización femenina de las palabras en términos de «inviolables doncellas» proyecta la fuerza de lo poético como un ejercicio viril que trastoca la imposibilidad o inviolabilidad en una experiencia creativa fecunda. El gesto viril de la reinvención aparece con los signos de interrogación que neutralizan primero y deconstruyen después las adjetivaciones idealizantes que pesan sobre la noción palabra. 
El segundo momento despliega al máximo la virilidad poética, pues se reemplaza la versión enigmática por una versión vitalista de las palabras que reafirma la lógica metapoética del texto. La metaforización que se vale del campo semántico de la naturaleza plantea el fundamento rítmico de dicha lógica, dada la particular correspondencia palabras-libélulas que remite inmediatamente a las sensaciones del movimiento y la vibración, $y$, en ese sentido, a la manifestación visual y sonora del escenario natural. Entonces, es la palabra-libélula que simboliza el vuelo o el tránsito de la palabra pensada a la palabra materializada: las palabras imaginarias rozan la sien del poeta y se hacen sentir sonoramente, zumban para desestabilizar e invadir el silencio, para escapar de la cultura y su sedimentación, y, así, volver a la vida. La escritura poética es, por lo tanto, la puesta en acto de la imaginación que se interna en la selva densa del lenguaje para cazar la palabra anhelada, una vez que ha recobrado su condición silvestre.

Ambos momentos, por otro lado, ponen al descubierto la perspectiva positivista de la composición, pues se describe el acto poético desde las características y funciones de algunas prácticas científicas. De modo que el poeta parece fungir de arqueólogo que destierra y reaviva los restos verbales, y también de un amante de la biología que disecciona a las palabras para abrirlas y descubrir los misterios de su anatomía. Se superponen estas disciplinas científicas y el ejercicio poético para sintonizar la productividad artística con la productividad de los conocimientos que marcan el compás de la modernización del mundo, y en consecuencia para que la primera productividad sea repensada bajo otras lógicas y otros lenguajes. Esta reingeniería moderna de la poesía se desarrolla en las siguientes estrofas mediante una orientación cosmopolita que demanda el entramado feliz de los conocimientos ${ }^{7}$.

Las correspondencias que se han explorado hasta aquí entre la visión estética y la ficción poética de González Prada dejan, a modo de conclusión, la tarea imprescindible de revisar los fundamentos de la modernización de la tradición literaria peruana, puesto que, como se ha podido advertir, este autor representa a un tipo de agente creativo que no solo impulsó la renovación del lenguaje poético, sino sobre todo trazó unas líneas de pensamiento desde la que buscó redefinir la naturaleza y el grado de interacción de dicho lenguaje con las otras formas de conocimiento que se abrían paso durante las primeras décadas del siglo XX.

7 Si bien nos hemos centrado en algunos poemas de Minúsculas, con la intención de demostrar el valor metapoético fundacional de la primera entrega del autor, en su siguiente poemario también encontramos otros ejercicios ficcionales de ese corte. Rescatamos de Exóticas, por ejemplo, «En país extraño», «Cuartetos persas», «Desnudeces», «Musa helénica», «Entre el futuro y el pasado» $y$ «La idea». 


\section{REFERENCIAS BIBLIOGRÁFICAS}

Fernández, C. (2005). La poesía de Manuel González Prada y la conciencia crítica del poeta moderno. En C. Fernández. La soledad de la página en blanco. Ensayos sobre lírica peruana contemporánea (pp. 13-21). Lima: Fondo Editorial de la Facultad de Letras de la Universidad Nacional Mayor de San Marcos.

Ferrari, A. (2003). Manuel González Prada entre lo nuevo y lo viejo. En A. Ferrari. La soledad sonora. Voces poéticas del Perú e Hispanoamérica (25-40). Lima: Fondo Editorial de la Pontificia Universidad Católica del Perú.

Friedrich, H. (1974). Estructura de la lírica moderna. Barcelona: Seix Barral.

González Prada, M. (1985a). Libertad d'escribir. En M. González Prada. Obras (pp. 149-162). Tomo I, Vol. I. Lima: Ediciones Copé.

(1985b). Escribas y retóricos. En M. González Prada. Obras (pp. 355-359). Tomo I, volumen I. Lima: Ediciones Copé.

(1985c). Notas acerca del idioma. En M. González Prada. Obras (pp. 254-268). Tomo I, volumen I. Lima: Ediciones Copé.

(1985d). La poesía. En M. González Prada. Obras (pp. 333-344). Tomo I, volumen I. Lima: Ediciones COPÉ.

(1985e). Víctor Hugo. En M. González Prada. Obras (pp. 181-190). Tomo I, volumen I. Lima: Ediciones Copé.

Copé.

(1988). Obras. Tomo III, volumen 5. Lima: Ediciones

Lino Salvador, E. (2013). El ritmo y la modernización de la lírica peruana. Los casos de González Prada, Eguren y Valdelomar. Lima: Fondo Editorial USIL.

Mariátegui, J. C. (1980). 7 ensayos de interpretación de la realidad peruana. Lima: Amauta.

Salazar Bondy, S. (2014). La poesía nueva del Perú. En S. Salazar Bondy. La luz tras la memoria. Artículos periodísticos sobre literatura y cultura (19451965) (pp. 275-283). Tomo I. Lima: Lápix Editores. 